\title{
IS FREE WILL SCEPTICISM SELF-DEFEATING?
}

\author{
Simon-Pierre Chevarie-Cossette \\ King's College London
}

Original scientific article - Received: 29/05/2019 Accepted: 11/11/2019

\section{ABSTRACT}

Free will sceptics deny the existence of free will, that is the command or control necessary for moral responsibility. Epicureans allege that this denial is somehow self-defeating. To interpret the Epicurean allegation charitably, we must first realise that it is propositional attitudes like beliefs and not propositions themselves which can be self-defeating. So, believing in free will scepticism might be selfdefeating. The charge becomes more plausible because, as Epicurus insightfully recognised, there is a strong connection between conduct and belief - and so between the content of free will scepticism (since it is about conduct) and the attitude of believing it. Second, we must realise that an attitude can be selfdefeating relative to certain grounds. This means that it might be self-defeating to be a free will sceptic on certain grounds, such as the putative fact that we lack leeway or sourcehood. This charge is much more interesting because of the epistemic importance of leeway and sourcehood. Ultimately, the Epicurean charge of self-defeat fails. Yet, it delivers important lessons to the sceptic. The most important of them is that free will sceptics should either accept the existence of leeway or reject the principle that "ought" implies "can".

Keywords: Free will scepticism, self-defeat, self-refutation, leeway, sourcehood, Epicurus, "ought" implies "can", responsibility, reasons 


\section{Introduction}

Free will scepticism is the doctrine that we do not have free will, i.e. the kind of command or control of our own conduct that we would need in order to be morally responsible for it. ${ }^{1}$ The concept of free will allows for different more precise conceptions. It is sometimes understood as the ability to choose amongst real alternatives or, as philosophers say, leeway, ${ }^{2}$ and it is sometimes understood as being the source of one's conduct. ${ }^{3}$ Thus, sceptical arguments typically conclude that free will does not exist, on the grounds that we lack leeway or that we are not the source of our actions.

Denying the existence of free will broadly defined might seem unthinkable to us. Radical as it stands, free will scepticism must be wrong. ${ }^{4}$ But if it is so radical, could it be turned against itself like some other sweeping philosophical doctrines? Several philosophers in history took up this challenge. ${ }^{5}$ Their arguments do not share a common philosophical lexicon. Nor do they always target free will scepticism explicitly - they often target determinism. But if they are sound, it is self-defeating to believe in free will scepticism, whether it is true or false. Since Epicurus first marshalled these arguments, let us call them 'Epicurean arguments.'

This paper is slightly unusual in that it does not belong to a contained contemporary debate where it could make a very specific contribution. Few philosophers after the 70s took Epicurean arguments seriously. Those who did proposed complex reconstructions which relied on a vast array of controversial views about epistemology and free will. ${ }^{6}$ Going back to the simple argument of Epicurus, distilling its general idea, and using it to regiment refined but simple Epicurean arguments is my first goal. My second goal is to assess how the sceptic might respond to each type of argument and to unearth what she might already learn. I ask the reader to judge this critical engagement as it is: a precocious step in a nascent literature.

Here is the game plan to meet my two goals. I start with Epicurus' own argument (\$2) and discuss what it means to be self-defeating. I then move to reconstructing the argument in the most charitable way (§3). This

\footnotetext{
${ }^{1}$ See e.g. Strawson (1994), Waller (2011), and Pereboom (2001; 2014a).

${ }^{2}$ See e.g. Vihvelin (2013) and van Inwagen (2017).

${ }^{3}$ See e.g. Frankfurt (1971) and Fischer (1994).

${ }^{4}$ For a recent discussion of the parallels between a dogmatic response to free will scepticism and to scepticism, see Chevarie-Cossette (forthcoming).

${ }^{5}$ See e.g. Hinman (1979), Dworkin (2011), Slagle (2016), and Lockie (2018).

${ }^{6}$ See e.g. Lockie (2018) and Slagle (2016).
} 
gives rise to arguments related to sourcehood (\$4) and leeway (§5), which I examine in turn.

\section{Epicurus' Argument}

About the view that all comes to pass by necessity, Epicurus argued:

This sort of account ( $\lambda$ ó $\gamma \circ)$ is self-refuting ( $\tau \rho \varepsilon ́ \pi \omega \pi \varepsilon \rho \iota \kappa \alpha ́ \tau \omega)$, and can never prove that everything is of the kind called 'necessitated'; but he [the sceptic or the determinist] debates this very question on the assumption that his opponent is

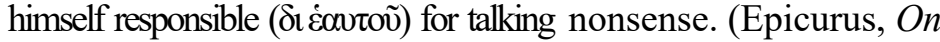
Nature. XXV, 34; translation Annas, Taylor, and Sedley 1983, 19-23)

To extract the best possible argument from this passage, we need to answer two questions. First, who does the Epicurean criticise: the determinist or the free will sceptic? Second, what does the Epicurean criticise this target for: making a discourse, maintaining a belief, or posing an action? For simplicity, call these two things respectively the target and the object of the Epicurean arguments.

\subsection{The Target and Object of Epicurus' Argument}

The official target of Epicurus is the Stoic who endorses the doctrine of necessity. This doctrine approximates physical determinism, the thesis that the conjunction of all the physical states in a given time slice and the laws of nature determines the states in any other time slice. However, Epicurus' argument is mostly worrying to determinists who also believe that determinism undermines free will, namely hard determinists - as opposed to determinists who do not, namely soft determinists.

Why? Epicurus' argument, as we will soon discover, turns on the claim that rationality or reason requires free will (whether sourcehood or leeway). The soft determinist may simply respond to Epicurus that the apparent, though illusory, difficulty of reconciling determinism with rationality is entirely inherited from the apparent, though illusory, opposition between determinism and free will. But this response is unavailable to the hard determinist. The hard determinist must be an incompatibilist between determinism and free will but a compatibilist between determinism and rationality. This is the real challenge. So, there is no doubt that, if Epicurean arguments work, they work against hard determinists. The most charitable reconstruction of Epicurean arguments 
thus reads them as primarily targeting hard determinists. ${ }^{7}$ To simplify, I will consider that the target of Epicurus extends to all free will sceptics. For one thing, sceptics typically admit the possibility of determinism; for another, Epicurus' argument hinges on the alleged consequences of determinism for free will (or responsibility), not on determinism itself.

Moving to the object of the argument. In the passage, Epicurus focusses on the sceptic's logos ( $\lambda$ ó $\gamma \circ \varsigma)$. But logos is famously ambiguous and suggests at least two possible translations. It could mean 'account', i.e. the sceptic's doctrine; or it could mean 'reasoning, i.e. the sceptic's inference or belief from reasons. What is wrong with this account or with this reasoning? They are described as trepetai egkalein (' $\tau \rho \varepsilon ́ \pi \omega ~ \pi \varepsilon \rho \iota \alpha \alpha ́ \tau \omega ')$, a technical term which literally translates as defeating upside down. Translators talk about 'self-refutation' or 'self-defeat', but what does that mean?

\subsection{Self-Defeat and Self-Refutation}

To understand Epicurus' argument, we must distinguish self-refutation from self-defeat and their respective objects. ${ }^{8} \mathrm{~A}$ proposition (or an account) is self-refuting, in one common sense of the term, just when it is contradictory because it applies or refers to itself; for instance, 'No universal proposition is true'. Similarly, an argument is self-refuting just when it is unsound because it applies or refers to itself; for instance, 'single-premise arguments are invalid; therefore, single-premise arguments are invalid'.

Free will scepticism is not self-refuting in this sense, since it is neither contradictory nor self-referential. The arguments supporting free will scepticism are not self-refuting either: while they might be unsound, this is not because they apply or refer to themselves. This suggests that when Epicurus attacks the sceptic's logos, he does not mean her 'account'.

However, there might be epistemic problems with believing or reasoning (in the sense of reasoning to a conclusion) that free will scepticism is true. After all, this is what Epicurus' argument suggests: that the content of a doctrine interacts with the epistemic attitudes of its proponent in an unfortunate way.

This is where the notion of self-defeat is relevant; for its object is precisely attitudes like beliefs or inferences rather than abstracta like propositions or

\footnotetext{
${ }^{7}$ Cf. Slagle (2016, 17, 28, 201-202) and Lockie (2018).

${ }^{8}$ In this, I follow Slagle's distinction (2016, 41-43).

9 This conforms to Mackie's account (1964); see also Page (1992, 423).
} 
accounts. There are two kinds of case of self-defeating propositional attitudes like belief. First, imagine Tommy, an undergraduate philosophy student who, fortunately for our purpose and unfortunately for his peers, likes to embrace the most radical theses he encounters. Today he believes that he has no beliefs. The fact that he believes this proposition ensures ${ }^{10}$ that it is false. Tommy's belief is 'self'-defeating in the sense that the believing (the attitude) defeats what is believed (the content) - see Act defeats content below. Second, imagine that Tommy acquires the belief that he would not acquire a single justified belief that day. Even assuming that this is true, Tommy's belief is self-defeating. The presumed truth of Tommy's belief ensures that he believes it inadequately, e.g. without justification, irrationally, unreasonably, etc. Tommy's belief is 'self'defeating in the sense that the truth of what is believed (the content) precludes the believing (the attitude) from being adequate-see Content defeats act below.

Thus, self-defeat is a property which, when it applies to beliefs, plays on an act/object ambiguity. It is either the attitude of believing which ensures that the belief content is false or, alternatively, it is the alleged truth of the belief content which ensures that the attitude of believing is inadequate. In light of this, it is no surprise that the object of Epicurus' argument was uneasy to identify.

A last remark: a belief is based on some grounds and those grounds are sometimes relevant to whether it is self-defeating. Last week, Tommy came to think that he was hopeless at remembering events in the distant past. That's fine. But Tommy formed his belief on the grounds that, when he was eight, he forgot his best friend's name four times. Now, this is problematic. Tommy's belief could well be true; and this time, it could be adequate if it was differently grounded. But the presumed truth of the belief content ensures that the believing is inadequate, grounded as it is. Thus, whether a belief is self-defeating is relative to the grounds on which it is believed. ${ }^{11}$

The following definition captures our remarks. (The same applies to inferences.)

\footnotetext{
${ }^{10}$ One might read 'ensures that' as 'is a sufficient reason for', 'explains why', 'grounds', or 'makes'.

${ }^{11}$ Some might think that this remark stretches the notion of self-defeat since the grounds of a belief is something external to it and so cannot contribute to self-defeat. Yet what a belief contains is contentious: a belief in the same proposition but which has been rebased on other grounds is not obviously the same belief. When I say that a belief is self-defeating, I use this broader view of what a belief contains.
} 
Self-defeating beliefs $=_{\text {df }}$ Suppose that a subject $S$ believes that $p$ on the grounds that $q$. Then, $S$ 's believing that $p$ is selfdefeating if and only if either:

(Act defeats content) The fact that $S$ believes that $p$ on the grounds that $q$ ensures that $p$ is false; or,

(Content defeats act) The presumed truth of $p$ ensures that $S$ believes that $p$ on the grounds that $q$ inadequately. ${ }^{12}$

What is an adequate belief? For the purpose of this discussion, I will assume that it is a belief which is rational or reasonable. For our purpose, I find it useful to understand rationality in believing as believing according to some rules of rationality and reasonableness in believing as believing on good grounds or for good reasons.

I also think that self-defeating beliefs are beliefs that we should dispose of, at least upon recognising that they are such. This is because they are beliefs which generally fail to be reasonable. Typically, a self-defeating belief is unreasonable in that it implies that it is unsupported by reasons: so either it is false or unsupported by reasons. Upon discovering this fact, we lose any reason to maintain this belief (see Chevarie-Cossette 2019). ${ }^{13}$

\section{Reconstructing the Epicurean Argument}

We now have some tools to provide a charitable interpretation of Epicurus' claim. ${ }^{14}$ Free will scepticism is not self-refuting, for there is nothing contradictory or self-referential about the thesis that free will does not exist. However, free will scepticism is a thesis that concerns conduct, but which extends to attitudes. The suggestion is that there is an unfortunate interaction between the content of the thesis of free will scepticism and the attitude of believing or inferring. This is crucial: a key to all Epicurean arguments is a connection between conduct and beliefs.

So, free will scepticism might be self-defeating to believe in. But if this is true, this cannot be in virtue of the fact that to believe it makes it false (as in Act Defeats Content). What remains is the possibility that the presumed

\footnotetext{
${ }^{12}$ I have presented this account elsewhere (Chevarie-Cossette 2019).

${ }^{13}$ We should note however that some philosophers still insist that they can reasonably question the existence of reasons (Olson 2014, chap. 9; cf. Cuneo 2007, chap. 4). The question turns essentially on whether reasons are inherently normative and on whether we can, in distinguishing reasonable from unreasonable beliefs, use a non-normative notion like evidence.

${ }^{14}$ There is also a plausible moral interpretation of Epicurus' argument, but I leave it aside for our purpose.
} 
truth of free will scepticism (perhaps combined with something else) ensures that one does not rationally or reasonably believe it (Content Defeats Act). Why would this be true? The most straightforward explanation is that rationality or reasonableness requires free will. ${ }^{15}$

This explanation sits well with another remark of Epicurus on the topic:

The man who says that all things come to pass by necessity cannot criticise $(\dot{\varepsilon} \gamma \kappa \alpha \lambda \dot{\varepsilon} \omega)$ one who denies that all things come to pass by necessity: for he admits that this too happens of necessity. (Epicurus, Extant Remains, Frag. XL; translation Bailey 1926, 112)

According to this point, the sceptic cannot legitimately criticise her opponent. This is because in trying to persuade her opponent, the sceptic is appealing to her opponent's rationality; but, again, rationality implies free will. ${ }^{16}$ So, in order to convince someone of a doctrine, the free wil sceptic must presume its falsehood.

We need not focus on this dialectical problem. If it is self-defeating to rationally persuade someone to be a sceptic, it has everything to do with the rational character of persuasion and nothing to do with its interpersonal character (cf. Castagnoli 2007, 16). So we should ask again: is it true that rationality or reason implies free will?

It seems, after all, that I can rationally believe that $2+2=4$ without having free will, i.e. the command or control necessary for moral responsibility. Here are two pro tanto reasons to strengthen this impression. First, there seems to be no necessary opposition between rational belief and constrained belief. Quite the opposite, constraint seems like a part of rationality, as Nozick (1981, 4-8) and James noted (1912, 168-169): to give in to forceful or knockdown arguments, or to be forced to a conclusion, is not irrational at all. Second, there seems to be no necessary opposition between rational action and unfree action (in the sense of an inner freedom). A heroin addict in rehabilitation acts rationally in taking the safe dose given by a doctor, regardless of whether he has the command or control to refuse to take it. If there is no opposition between rationality on the one hand and coercion or absence of inner freedom on the other hand,

\footnotetext{
${ }^{15}$ By 'free will', it is important to insist that I mean nothing more than the command or control necessary for moral responsibility. Otherwise, this would be an anachronistic interpretation of Epicurus. See Bobzien (2000) and Frede (2011).

${ }^{16}$ Again, there is also a moral interpretation of this argument according to which it is unfair to criticise someone for not being a free will sceptic.
} 
it is unclear that there is an opposition between rationality and absence of free will.

We can however refine our explanation of why it is self-defeating to believe in free will scepticism. Epicurus targeted the free will sceptic's logos or reasoning. But we reason from premises and we believe on certain grounds. Now, the grounds or premises for which one is a free will sceptic includes or implies the proposition that humans lack leeway or sourcehood. The Epicurean can take advantage of these points. She does not need to argue that the existence of rationality or reason implies the existence of free will, understood generally. She can instead argue more narrowly that either leeway or sourcehood implies rationally. Thus, believing in free will scepticism on the grounds that we lack leeway or sourcehood is selfdefeating.

\section{Sourcehood}

Epicurus himself was a sort of sourcehood theorist. In fact, he claimed that the sceptic debates the question of responsibility 'on the assumption that his opponent is himself responsible ( $\delta \mathrm{t} \dot{\varepsilon} \alpha v \tau$ oṽ) for talking nonsense.' The Greek for 'responsible' is $\delta 1 \dot{\varepsilon} \alpha v \tau o \tilde{v}$ (di eautou), which means 'because of himself' - as opposed to because of something external (see Bobzien 2000, 291-292). This is sourcehood. So, according to Epicurus the sceptic cannot argue that we are never the source of our conduct because this presumes that she is not the source of her reasoning or belief. This is supposed to be self-defeating.

What is it to be the source of one's conduct? The contemporary literature gives us two main answers. We are the source of our conduct when our actions and omissions stem from reason-responsive mechanisms (see e.g. Fischer 1994; Hurley 2003; Sartorio 2016). Alternatively, we are the source of our conduct when our actions and omissions are the product of some of our desires or our values - something to which we identify or which belongs to our 'real selves' (see, e.g., Frankfurt 1971; Shoemaker 2015). So, the first view emphasises reason while the second emphasises identification or ownership. ${ }^{17}$

There is a sceptical concern corresponding roughly to each answer. The first is that reasons are irrelevant to the explanation of our conduct: our conduct, including our reasons for action, can be entirely accounted for in

\footnotetext{
${ }^{17}$ These answers are not exclusive: for instance, Fischer endorses an endorsement condition on responsibility.
} 
terms of physical events. Call this the exclusion concern. The second concern is that our conduct does not ultimately belong to our real selvesor if it does, this is partly insignificant-because our conduct is ultimately determined by events outside of our control. The same goes for reasons for which we act. Call this the ownership concern. The two concerns are importantly linked: the exclusion concern makes the radical claim that we never act for reasons; the ownership concern leads to the less radical view that we never act for reasons that are ultimately ours. In a word, the first concern casts doubt on reason for conduct; the second on ownership of these reasons. Each sceptical concern gives rise to an Epicurean argument.

\subsection{Exclusion}

The exclusion concern about reasons stems from so-called exclusion arguments about mental states (see, e.g., Kim 2007). Roughly, mental states seem to be unidentical to physical states and yet realised in them. But then the cause of our conduct could be entirely accounted for in terms of physical states. This leaves no causal role to be played by our mental states. The conclusion is not that mental states do not exist, but rather that we have no reason to think that they have a causal effect.

The same argument applies more specifically to our reasons. For the purpose of this discussion, I understand reasons as facts which explain or favour other facts (or which explain both normative and non-normative facts). And I understand our reasons as pieces of knowledge or justified beliefs in these reasons. When $S$ acts for reason $R, S$ acts because $S$ knows $R$ or because $S$ is justified in believing $R$. Imake these plausible ${ }^{18}$ assumptions for simplicity's sake. On this picture, if mental states have no causal role, nobody acts for a reason. It vindicates free will scepticism.

The worry is that if our reasons have no causal role on our conduct, the same applies for our beliefs, including our belief in free will scepticism. This Epicurean response was most famously made by Karl Popper (and has not been much discussed in the recent literature):

$[\mathrm{P}]$ hysical determinism is a theory which, if it is true, is not arguable, since it must explain all our reactions, including what appears to us as beliefs based on arguments, as due to purely physical conditions [...]. But this means that if we believe that we have accepted a theory like determinism because we were swayed by the logical force of certain arguments, then we are deceiving ourselves, according to

\footnotetext{
${ }^{18}$ See Hyman (2015) and Alvarez (2017).
} 
physical determinism [...]. (Popper 1972, 223-224, emphasis is mine; see also Lockie 2018, chap. 10)

Thus, it is self-defeating to believe in free will scepticism because if it were true, it would follow that we do not believe it for a reason, since we believe only because of natural events. (Popper's use of 'purely' is supposed to mark an exclusion.)

Popper was right to maintain this connection between actions and beliefs. If we never act for reasons, we never believe for reasons. If my giving to charity being caused by a natural event is incompatible with (or if it excludes) my giving to charity for a moral reason, then my believing that I should give to charity being caused by a natural event is incompatible with (or it excludes) my believing it for a moral reason. For, in general, what counts as a reason to act can also count as a reason to believe. The fact that wealth is unequally distributed in our society is both a reason to give to charity and to believe that we should do so. And once we know that wealth is unequally distributed, then it becomes our reason to act and believe. What counts as a cause for a belief can also count as a cause for an action. The Wall Street Crash of 1929 caused many people to believe that they had lost their fortune; and it caused Roosevelt to propose his New Deal. And what counts as acting or believing for a reason must include some sort of causal connection between an agent's holding to that reason and her action or belief.

This clear but admittedly controversial picture leaves no room for an asymmetry that the free will sceptic could exploit in responding to the Epicurean. This suggests that the Epicurean has a sound argument:

\section{The Reason Argument}

If everyone acts because of natural events rather than for reasons, everyone believes because of natural events rather than for reasons.

If everyone believes because of natural events rather than for reasons, no one believes rationally.

Therefore, if everyone acts because of natural events rather than for reasons, no one believes rationally that free will scepticism is true.

I have just discussed the first premise, which is the typically Epicurean premise that connects conduct and beliefs. And the second rests on a natural connection between rationality and reasons and on the fact that by 'rather', I signal an incompatibility. As I indicated, it follows that believing 
in free will scepticism on a certain ground is self-defeating, the ground being that we act because of natural events rather than for reasons. This is all I need to show for my purpose:

First lesson: The free will sceptic cannot and should not rely on the doubtful claim that we act because of natural events rather than for reasons.

So free will sceptics should try, as we all should, to find a way out of the exclusion concern.

Since the problem is general and applies to all mental states, the free will sceptic will not be able to solve it by drawing distinctions between different kinds of explanations or reasons. True, she can insist - as did Ayer (1963, 266-267) and Wolf $(1993,72)$ - that something can be both caused and justified. If I ask you 'why do you believe that Italian is the most beautiful language?', you may both respond that it is because you spent some time in Italy (which merely explains your belief) or that it is more colourful than any other language (which justifies your belief). But this does not help to deal with the exclusion concern. This is because action or belief for a reason (because I am justified) must make room for the causal role of reasons; and this causal role is precisely what the exclusion concern targets.

\subsection{Ownership}

We now move to the second sceptical concern and its corresponding Epicurean argument. The concern is that even if we act for reasons (contra the exclusion concern), these reasons - and so our actions - are not truly ours since they can all be ultimately explained by facts or events foreign to us. Alternatively, even if some reasons (or desires and values) were ours, this would not mean much since our having these reasons would not ultimately be up to us (see Strawson 1994; Pereboom 2014a).

The Epicurean can respond to this challenge, again by connecting actions and beliefs. If our actions and our reasons for action are foreign to us, so are our beliefs. But then our beliefs do not stem from our reasons and threaten to be irrational. ${ }^{19}$ The argument can be put in terms of sourcehood:

${ }^{19}$ See Kant (Groundworks 4: 448) for the claim that foreign influence is incompatible with the work of reason. 


\section{The Sourcehood Argument}

If no one is the adequate source of their conduct, no one is the adequate source of their beliefs.

If no one is the adequate source of their beliefs, no one believes rationally.

Therefore, if no one is the adequate source of their conduct, no one believes rationally that free will scepticism is true.

The first premise is the typically Epicurean connection between conduct and beliefs. I shall argue that although the Epicurean is right to connect beliefs and actions in this way, she is wrong to think that moral free will (or responsibility) and rationality each requires sourcehood in the same sense. In a word, the Sourcehood Argument equivocates.

To be the adequate source of her conduct in the sense relevant to responsibility and free will, a subject must first be the source of her conduct. Her conduct must stem from her. Thus, it cannot be the direct result of an external factor such as someone pushing her. Nor can it be the direct result of an internal factor which is not the agent's, such as an uncontrollable impulse or a disease. For a similar reason, someone who acts under duress is not the adequate source of her action: this action does not really stem from her in the relevant sense. It somehow is the action of the coercer (Nozick 1997, 38).

But this is not enough. A child soldier who participates willingly in an act of war is still not the adequate source of his conduct. He did not make himself; and the commitments that he manifests in his violent behaviour are not fundamentally his. Some sceptics suggest that this is because the child is not the source of the source of his conduct (see Strawson 1994; Pereboom 2014a). To use Hurley's phrase (2003), the free will sceptic (and some incompatibilists) requires that to be responsible for $\Phi$, someone be responsible for the causes of $\Phi$. Now, to be responsible for $\Phi$ or to be the source of $\Phi$, a subject does not need to be responsible for or be the source of everything that leads to $\Phi$. The subject must be responsible for or be the source of what determines that she will $\Phi$ (see Istvan 2011). This still leads to a regress, unless the causal chain can stop in the agent's free act of willwhich the sceptic denies. The subject's conduct is ultimately determined by something that she is not the source of - and so for which she is not responsible. The subject will never be the ultimate source of her conductshe will never be truly responsible. ${ }^{20}$

${ }^{20}$ For a similar reasoning, see Galen Strawson (1994) and Istvan (2011). 
Free will sceptics can say the very same thing about beliefs: to be the adequate source of them, we need to be the adequate source of their cause. But it leads again to a regression: for the causal chain continues up until a point where we no longer are the adequate source of the thing we are considering. Since this reasoning is just as plausible - no more, no lessfor beliefs and for conduct, the first premise looks true: if no one is the adequate source of their conduct, no one is the adequate source of their beliefs.

Now, the second premise also seems true. Believing for good reasons or on adequate evidence is generally insufficient to believe rationally. For this, a subject must usually believe for good reasons that are her own-on her evidence. If Detective Chief Inspector Japp does not believe that there is an earring in the room, then it would be irrational at best of him to believe that the killer is a woman on the grounds that there is an earring in the room. Japp clearly needs to acquire the evidence or the reason - that he makes it his-and this in turn implies that he forms the relevant belief or that he comes to know the relevant fact.

For this, one might think, Japp needs again to believe on his evidence or for his reasons. And this might look like it causes a regress which shows that rationality, just like responsibility, is impossible. Yet this is mistaken. The fact that, to believe rationally, Japp needs to believe for his reasons does not imply that the reasons for which he believes must have been acquired because of a further reason that was his own. Why? There are two classic answers to this. The foundationalist (most notably Aristotle) claims that there might be self-evident reasons or special pieces of evidence that Japp acquires simply by paying attention to them. The existence of these things clearly has nothing to do with free will or determinism. The coherentist (such as Blanshard) claims that a series of belief can justify each other in a circle. Again, whether someone holds coherent beliefs has nothing to do with free will and determinism. The foundationalist can claim that while a responsible action requires a further responsible action ad infinitum, it is clear that a justified belief does not require a further justified belief ad infinitum. And a coherentist can claim that while justification can stem from the coherence of a set of beliefs, responsibility cannot stem from the coherence of a set of actions.

This means that, whether coherentist or foundationalist in nature, the structure of justification differs from the structure of responsibility. What is required for justification differs fundamentally from what is required for free will. Only the former can plausibly give rise to an infinite regression. We saw that there is a sense in which the concept of 'adequate sourcehood' is fitting in both the case of responsibility and of justification since each 
implies a kind of ownership. But since the structure of justification is so different from the structure of responsibility, this strongly suggests that 'sourcehood' does not refer to the same property in each case or that the standards of adequacy differ fundamentally from premise 1 to premise 2 .

The sceptic can therefore insist that the Sourcehood Argument equivocates: rationality requires sourcehood or adequacy in a different sense than moral responsibility (according to the sceptic). It is not, then, that 'adequate sourcehood' always means something different when it applies to actions and when it applies to beliefs. The Epicurean is right to maintain a symmetry between these things. Rather, 'adequate sourcehood' is different whether we are talking about what is necessary for moral responsibility and whether we are talking about what is necessary for rationality.

Despite having refuted the Sourcehood Argument, the free will sceptic has a concession to make. She must concede that when some compatibilist argues that we have free will because, roughly, we act for our own reasons, he is partly right. We do act for our own reasons, in the same sense that we believe for our own reasons. But this sourcehood, the sceptic must then argue, is different from the sourcehood necessary for moral responsibility. In a word:

Second lesson: The free will sceptic must recognise the existence of some property of sourcehood, one that is necessary for people to believe and act for their own reasons and rationally.

The Sourcehood Argument fails but it urges the sceptic to explain why responsibility and justification use different notions or standards of sourcehood.

\section{Leeway}

As I indicated previously, some philosophers doubt the existence of free will on the grounds that we lack leeway. It suffices for our purpose to roughly indicate why. Typically, the leeway sceptic combines the Consequence Argument (see, e.g., van Inwagen 2017) and the Mind Argument (see, e.g., Pereboom 2014a). The Consequence Argument claims roughly that if determinism is true, then our actions are the consequence of the remote past and of the laws of nature. Thus, to act differently, we would need to change the laws of nature or the distant past, which is impossible. The Mind Argument says, crudely, that indeterminism is determinism plus chance, which is irrelevant to our abilities. Therefore, we lack the ability to do otherwise. 
This suggests an Epicurean argument:

If pessimistic determinism [free will scepticism] were true, no one could responsibly think that he had made a wise [or rational] decision in believing it. He had no choice but to believe it. (Dworkin 2011, 225, my emphasis)

The notion of choice is obviously tied to that of alternatives: Dworkin is not merely talking about the mental event of choosing, but the selection of one amongst several courses of action. Dworkin tells us, without much argument, that wisdom requires leeway.

A stronger philosophical treatment is given by Robert Lockie:

[I]f determinism is true, then no-one can do otherwise and therefore no-one may reason otherwise. Assuming that the ability to reason otherwise is necessary for someone to be held epistemically irresponsible, no-one may then be held responsible for their intellectually wrong actions or unjustified, irrational cognition. But if no-one is responsible for their unjustified cognition, then no-one is epistemically justified either - in the intended, internalist sense. [...] So one cannot be epistemically justified in claiming that determinism is true. (Lockie 2018, 183; my emphasis, premise numbering omitted $)^{21}$

I shall argue that there is a simplified and less ambitious version of Lockie's argument. This argument does not suppose, controversially, that determinism is incompatible with leeway; it does not dip into the question of epistemic responsibilities; and it does not tackle the difficult topic of 'holding' responsible. My argument simply captures Lockie's insight that rationality ('internalist justification') requires leeway because leeway is required for obligations (responsibilities).

That leeway implies rationality cannot be established directly: it is false that if one believes a proposition rationally, one could have believed otherwise. A subject could believe a proposition rationally in the absence of any kind of leeway. Thankfully, most of us would be incapable of

\footnotetext{
${ }^{21}$ In this chapter, Lockie discusses two related arguments, but they are of a different kind. The first (179) concludes that determinists cannot accept deontic ethics; the second (about the lazy argument, 178) fundamentally makes the claim that in deliberating we must presume that we have options.
} 
disbelieving that $2+2=4$ and yet nothing impedes (directly) the rationality of our belief that $2+2=4$. We need an indirect argument.

\subsection{The Leeway Argument}

The Epicurean can pursue an indirect strategy and claim that if one irrationally believes a proposition, one could have believed otherwise. This principle is more plausible. For, suppose that a subject believes that $2+2=5$ and could not believe otherwise. Then, the Epicurean may still declare that this subject's belief is not rational: it is perhaps arational, but not irrational.

Why would the Epicurean say this? Irrationality, she can say, implies a failure to satisfy obligations to believe and if leeway does not exist, then these obligations do not exist either. Why does the inexistence of leeway imply the inexistence of obligations? The Epicurean says: first, if we can never do or believe otherwise, we never have the obligation to do or believe otherwise because 'ought' implies 'can' (henceforth OIC). Second, if we never have the obligation to do or believe otherwise, we have no obligations at all: we want to leave aside the abstruse view that we only have the obligation to perform the acts that we in fact perform and to believe the propositions that we in fact believe (this only make sense for a saint).

Once we have admitted that the inexistence of leeway implies the inexistence of irrationality, we should admit that it implies the inexistence of rationality in general. Rationality and irrationality go hand in hand. This explains why it is quite natural to think that animals and toddlers are arational rather than irrational. This does not have to mean that for one to rationally believe that $2+2=4$ one is able to believe otherwise in this situation; it simply means that the existence of rationality in general implies the existence of irrationality in general. ${ }^{22}$ We can make sense of the philosophical view that rationality and irrationality do not exist: rationality would be a property without extension (perhaps because there are no norms of rationality) and irrationality would not exist because irrationality is absence of rationality where rationality could apply. Everything would be arational because arationality means the absence of rationality where rationality could not apply (e.g. the table is arational). But to make sense of the view that rationality exists, but not irrationality, we would need to imagine that if rationality can apply, then it exists. This only works in an ideal world, a place we do not live in.

${ }^{22}$ This argument might recall the theistic argument that the existence of evil implies the existence of the good. 
It is now helpful to summarise the argument:

\section{The Leeway Argument}

If no one has leeway, there are no obligations.

If there are no obligations, no one believes irrationally.

If no one believes irrationally, no one believes rationally.

Therefore, if no one has leeway, no one believes rationally that free will scepticism is true.

Here again we have a typically Epicurean connection between conduct and beliefs in the two first premises (since 'no one has leeway' is at least partly about conduct).

If the Leeway Argument is sound, it follows that it is self-defeating to believe that free will scepticism is true on the grounds that we have no leeway. The presumed truth of free will scepticism ensures that either it is believed on false grounds (since we have leeway) or that it is not believed rationally (since we have no leeway and thus cannot believe rationally).

It is worth insisting at this point that, although the sceptic could admit the existence of leeway and find other grounds for her doctrine, this is a major consequence. As we just saw, some of the main arguments for free will scepticism feature leeway. And, although many sceptics ${ }^{23}$ and non-sceptics ${ }^{24}$ are now sourcehood theorists, they often concede in passing that, in a sense, we lack leeway. If the Leeway Argument is sound, this is problematic; belief leeway needs to be maintained for rationality.

This means that the sceptic should try to find a way to refute the Leeway Argument. I suggest that she abandons OIC, although this might be mistaken. Let me simply point out that OIC is popular amongst free will sceptics (see, e.g., Pereboom 2014b, 222; cf. Waller 2011). Some sceptics have appealed to it in defence of another principle that is sometimes used by free will sceptics, the principle that we are only responsible if we could have done otherwise. ${ }^{25}$ And if free will sceptics were to concede that we can do otherwise, it might be harder to argue that we are not ultimately the source of our actions.

Instead of making this costly concession, the sceptic might want to follow a third way and declare that the Leeway Argument equivocates on the sense of 'obligation'. There are two ways to argue for this. The first is to

\footnotetext{
${ }^{23}$ See Pereboom $(1995,27 ; 2014 a, 138 ; 2014 b, 221)$.

${ }^{24}$ This might include semi-compatibilists like Fischer (1994).

${ }^{25}$ On this, see e.g. Widerker (1991) and Copp (2008).
} 
oppose obligations to believe and obligation to act and insist that the second but not the first requires leeway. The second is to oppose epistemic obligations and moral obligations and maintain that the second but not the first requires leeway. I consider each in the following subsections.

\subsection{Obligations to Believe, Obligations to Act}

We have some power over our conduct and so while it is controversial that an obligation to act implies 'can', it remains plausible. By contrast, obligations to believe, one might suggest, cannot imply 'can' because we have obligations to believe, but we do not control directly our beliefs. ${ }^{26}$ So, although we might have thought with the Epicurean that all obligations were similar in their requirements, this is incorrect: obligations to believe and to act are made of a different fabric.

While tempting, this counterargument is unavailable to our sceptic (and so there is no need to consider whether we directly control our beliefs). This is simply because the sceptic who accepts that we lack leeway, following the same reasoning, would have to conclude that the moral 'ought' does not imply 'can' either, since she denies the existence of leeway in conduct. But then the strategy is no longer a third-way escape focussing on the asymmetry between two kinds of obligations to preserve OIC. It throws OIC under the bus.

\subsection{Epistemic Obligations, Moral Obligations}

The contrast between epistemic and moral obligations might look more promising. As Clifford insisted, there are moral obligations to act, but also to believe. Similarly, there are epistemic obligations to believe, but there might also be epistemic obligations to act. So the epistemic/moral distinction cuts across the to believe/to act distinction. If I must choose between happily believing against my evidence and depressingly believing on my evidence, it is possible that the two kinds of normativity pull me in different direction. We can see this if we consider a case where a doctor could gather more evidence for the efficacy of a new vaccine or spend this time to administer it to patients. The general idea is that there are two kinds of normativity which aim at two kinds of value and which are subject to different requirements. Perhaps the anti-Epicurean can use this picture.

Her strategy would be to argue that moral, but not epistemic, obligations require alternatives. For this, the anti-Epicurean will try to show that epistemic normativity is like other 'minor' kinds of normativity. In fact, in

${ }^{26}$ This is precisely what Alston (1989) advocates. 
general, certain kinds of obligations, like obligations of etiquette and professional obligations, do not imply 'can.' The Dean of the Faculty might have an obligation to attend a meeting even if he cannot be presenthe might have been in a car accident. He thus fails to satisfy an obligation, although he is excused. To be sure, his work-description does not specify that his obligations are suspended if he is unable to meet them, at least, not in all cases where he lacks the relevant abilities. Similarly, etiquette certainly recommends that a guest show appreciation for a meal, but this might be impossible if a food allergy forces her to rush to the bathroom. An obligation was infringed, despite the excuse. And the epistemic 'ought' might be very similar to etiquette and professional obligations as regards 'can': "our friend in his tinfoil hat can't make himself stop overtly believing contradictions" (Carr 2015, 752). But, surely, our friend in his tinfoil hat is not believing rationally and therefore he infringes an obligation of rationality.

But then, can't we say the same thing of moral obligations? There is an analogous character to our friend in his tinfoil hat - the inexorably evil man with his dictator cap. Surely, he infringes his moral obligations - and so the moral 'ought' does not imply the moral 'can'. Remember however that the anti-Epicurean strategy here is to keep " "moral ought" implies "can"” and reject "'epistemic ought" implies can'. So she must insist that somehow the dictator does not have the true moral obligation to refrain from 'dictating.'

She can make the following case. True obligations imply can (perhaps because their infringement is blameworthy), and other obligations - such as professional obligations, chess obligations, and epistemic obligationsare just rules that it would be ridiculous to insist 'imply can'. What distinguishes our friend in his tinfoil hat from our foe in his dictator cap is that the first fails to follow epistemic rules whereas the second is not under moral obligations. ${ }^{27}$ Satisfying epistemic rules or rules of etiquette then has no intrinsic significance: it does not matter, in and of itself, whether one has rational beliefs or not. The significance of following those rules is quite unlike, for instance, the significance of finding meaning in one's life or of respecting others. Hence, it is no surprise if general principles like OIC do not apply to epistemic obligations (or rules).

I am disinclined to admit this response because I think that at least some epistemic statuses, as opposed to statuses of etiquette, bear intrinsic or final significance or value. To be fair, some false beliefs seem too negligible to matter for their own: whether I truly believe that there is an odd number of

\footnotetext{
${ }^{27}$ See Côté-Bouchard (2017).
} 
grains of sand on this beach is negligible. And yet, it seems that in general having true beliefs - but not following rules of etiquette - is intrinsically or finally significant or valuable. We think it is intrinsically or finally valuable to be connected with the world - we want to be guided by the truth. And this connection, just is an epistemic connection (see Hyman 2015, 209).

Now, to be sure, the proposition that knowledge or rationality is finally or intrinsically valuable does not entail that following epistemic obligations is. But this seems enough to close the gap between ethics and epistemology and to widen the gap between epistemology and etiquette. (After all, perhaps following moral rules has no intrinsic value. Perhaps it is only resulting states of affairs that have intrinsic value.)

We should add that the anti-Epicurean is in no position to insist too much on individual cases of valueless knowledge or of true belief. For a similar problem will appear in the case of morality. Imagine that we have a pair of cases of identical situations of horrible actions except that in the first, but not in the second, the villain could not have done otherwise, and so infringes no moral obligation. Just like it seems indifferent whether we have a true belief or an item of knowledge about the number of grains of sands, it seems indifferent whether we are in the first or in the second case-whether the villain is infringing an obligation. We should not infer from these sorts of cases that there is no real epistemic or moral normativity.

It seems, then, that sceptics have a solid case for the symmetry of moral and epistemic obligations regarding leeway. This takes us back to the two other options, which are costly to the sceptic. Thus, we can say:

Third Lesson: The free will sceptic must either: (1) accept that we may have leeway; or (2) reject OIC.

None of these avenues is blocked to the sceptic, but, as we have seen, each is at least prima facie very costly.

\section{Conclusion}

Epicurus' argument was prima facie tempting. There seemed to be something suspicious about claiming, on the one hand, that we have no free will but, on the other hand, engaging into fierce deliberation about what would be best and rational for us to achieve and believe. 
Trying to give the best reading of Epicurus' argument helped us to identify some of the arguments underlying this initial sentiment. There was something to it: not just a confused feeling, but sourcehood-related and leeway-related arguments concluding that to believe in free will scepticism is self-defeating. Yet none of the considered arguments was fully successful. That's a major point in favour of the free will sceptic.

Still, our discussion left the sceptic with three lessons:

First lesson: The free will sceptic cannot and should not rely on the doubtful claim that we act because of natural events rather than for reasons.

Second lesson: The free will sceptic must recognise the existence of some property of sourcehood, one that is necessary for people to believe and act for their own reasons and rationally.

Third Lesson: The free will sceptic must either: (1) accept that we may have leeway; or (2) reject OIC.

These lessons should be added to the sceptic's breviary. What is their significance? The third lesson makes it much harder to be a free will sceptic of the leeway kind; and the first lesson deprives the sceptic of an important argument (from the exclusion concern). The obvious way forward for free will scepticism seems therefore to revolve around the ownership concern, according to which we cannot be responsible for our conduct because even if we act for our reasons, desires, or values, they are not as much ours (or significantly ours) as we thought; in fact, we own them because of factors lying outside of our control. This might give confidence to the free will sceptics, who have mostly turned to this sort of view in the past decades (Strawson 1994; Pereboom 2001; Waller 2011; Pereboom 2014a). Yet sourcehood sceptics were mistaken in thinking that since leeway was not the crux of responsibility, they could deny the existence of leeway on top of sourcehood at no additional cost. ${ }^{28}$

Although, I did not have the chance to tackle this question seriously (see $\S 2.2$ ), I believe it would be a mistake for the sceptic to accept that her doctrine is self-defeating and insist that at least she has a true belief. After all, what made her view attractive was that she gave us powerful reasons to believe that some of our institutions are unjustified and some of our attitudes are irrational. To admit that being a sceptic is itself neither rational nor reasonable would undermine this. Free will scepticism is a philosophical doctrine supported by arguments, not a creed supported by hopes.

${ }^{28}$ See Pereboom (1995, 27; 2014a, 138; 2014b, 221). 


\section{Acknowledgements}

I wish to thank Ralf Bader, Charles Côté-Bouchard, Tanya Goodchild, Alison Hills, John Hyman, Clayton Littlejohn, and two anonymous reviewers of this journal for their invaluable comments on previous versions of this essay.

\section{REFERENCES}

Alston, W. 1989. Epistemic Justification: Essays in the Theory of Knowledge. Ithaca; London: Cornell University Press.

Alvarez, M. 2017. Reasons for action: Justification, motivation, explanation. The Stanford Encyclopedia of Philosophy. Edited by Edward N. Zalta. Accessed September 22, 2019. https://plato.stanford.edu/entries/reasons-just-vs-expl/

Annas, J., W. Taylor, and D. N. Sedley. 1983. Oxford Studies in Ancient Philosophy. Oxford: Clarendon Press.

Ayer, A.J. 1963. The Concept of a Person: And Other Essays. London: Macmillan.

Bailey, C. 1926. Epicurus: The Extant Remains. Oxford: Clarendon Press. Bobzien, S. 2000. Did Epicurus discover the free-will problem? Oxford Studies in Ancient Philosophy 19: 287-337.

Carr, J. 2015. Don't stop believing. Canadian Journal of Philosophy 45: 744-766.

Castagnoli, L. 2007. Everything Is True, Everything Is False: SelfRefutation Arguments from Democritus to Augustine. Antiquorum Philosophia 1: 11-74.

Chevarie-Cossette, S.-P. 2019. Self-defeating beliefs and misleading reasons. International Journal of Philosophical Studies 27: 5772.

Chevarie-Cossette, S.-P. Forthcoming. Knowing about responsibility: A trilemma. American Philosophical Quarterly.

Copp, D. 2008. "Ought" implies "can" and the derivation of the Principle of alternate possibilities. Analysis 68: 67-75.

Côté-Bouchard, C. 2017. Belief's Own Metaethics? A Case against Epistemic Normativity. KCL doctoral thesis.

Cuneo, T. 2007. The Normative Web: An Argument for Moral Realism. Oxford: Oxford University Press.

Dworkin, R. 2011. Justice for Hedgehogs. Harvard University Press.

Fischer, J.M. 1994. The Metaphysics of Free Will: An Essay on Control. Oxford: Blackwell.

Frankfurt, H. 1971. Freedom of the will and the concept of a person. The Journal of Philosophy 68: 5-20. 
Frede, M. 2011. A Free Will: Origins of the Notion in Ancient Thought. Berkeley; London: University of California Press.

Hinman, L. 1979. How not to naturalize ethics: The untenability of a Skinnerian naturalistic ethic. Ethics 89: 292-97.

Hurley, S. 2003. Justice, Luck, and Knowledge. Cambridge: Harvard University Press.

Hyman, J. 2015. Action, Knowledge, and Will. Oxford: Oxford University Press.

Inwagen, P. 2017. Thinking about Free Will. Cambridge: Cambridge University Press.

Istvan, M. 2011. Concerning the resilience of Galen Strawson's Basic argument. Philosophical Studies 155: 399-420.

James, W. 1912. The Will to Believe: And Other Essays in Popular Philosophy. Auckland: Floating Press.

Kim, J. 2007. Physicalism, or Something near Enough. Princeton: Princeton University Press.

Lockie, R. 2018. Free Will and Epistemology: A Defence of the Transcendental Argument for Freedom. New York: Bloomsbury Academic.

Mackie, J.L. 1964. Self-refutation: A formal analysis. The Philosophical Quarterly 14: 193-203.

Nozick, R. 1981. Philosophical Explanations. Oxford: Clarendon Press.

Nozick, R. 1997. Socratic Puzzles. Cambridge: Harvard University Press.

Olson, J. 2014. Moral Error Theory: History, Critique, Defence. Oxford University Press.

Page, C. 1992. On being false by self-refutation. Metaphilosophy. 23(4): 410-26.

Pereboom, D. 2001. Living Without Free Will. Cambridge: Cambridge University Press.

Pereboom, D. 2014a. Free Will, Agency, and Meaning in Life. Oxford: Oxford University Press.

Pereboom, D. 2014b. Responses to John Martin Fischer and Dana Nelkin. Science, Religion \& Culture 1(3): 218-25.

Popper, K. 1972. Objective Knowledge: An Evolutionary Approach. Oxford: Clarendon Press.

Sartorio, C. 2016. Causation and Free Will. Oxford: Oxford University Press.

Shoemaker, D. 2015. Responsibility from the Margins. Oxford: Oxford University Press.

Slagle, J. 2016. The Epistemological Skyhook: Determinism, Naturalism, and Self-Defeat. London and New York: Routledge.

Strawson, G. 1994. The impossibility of moral responsibility. Philosophical Studies 75(1/2): 5-24. 
Vihvelin, K. 2013. Causes, Laws, and Free Will: Why Determinism Doesn't Matter. Oxford: Oxford University Press.

Waller, B. 2011. Against Moral Responsibility. The MIT Press.

Widerker, D. 1991. Frankfurt on "ought implies can" and alternative Possibilities. Analysis 51: 222.

Wolf, S. 1993. Freedom within Reason. Oxford: Oxford University Press. 